\title{
Impactos ambientais da mineração no Estado de São Paulo
}

\section{ANDRÉA MECHI e DJALMA LUIZ SANCHES}

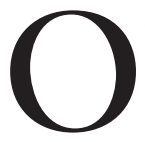

S MESMOS PROCESSOS geológicos que dão origem aos depósitos minerais condicionam a sua localização na crosta terrestre. A abundância ou escassez dos elementos que compõem essa crosta determina a frequência de ocorrência dos diversos tipos de depósitos minerais. A essas peculiaridades associase o termo rigidez locacional, que expressa a restrição na seleção de áreas que possam gerar menores impactos ambientais na implantação de empreendimentos minerários. Muitas vezes, os locais de ocorrência são ambientalmente sensíveis e importantes para a preservação da biodiversidade, dos recursos hídricos, da paisagem ou de demais recursos naturais com função ambiental de grande importância. Por esses aspectos, além da necessidade frequente de escavações vultosas para a retirada do bem mineral, que resultam em grandes volumes de rejeito, é que se vincula a mineração a impactos negativos significativos para o meio ambiente.

Praticamente, toda atividade de mineração implica supressão de vegetação ou impedimento de sua regeneração. Em muitas situações, o solo superficial de maior fertilidade é também removido, e os solos remanescentes ficam expostos aos processos erosivos que podem acarretar em assoreamento dos corpos d'água do entorno. A qualidade das águas dos rios e reservatórios da mesma bacia, a jusante do empreendimento, pode ser prejudicada em razão da turbidez provocada pelos sedimentos finos em suspensão, assim como pela poluição causada por substâncias lixiviadas e carreadas ou contidas nos efluentes das áreas de mineração, tais como óleos, graxa, metais pesados. Estes últimos podem também atingir as águas subterrâneas. O regime hidrológico dos cursos d'água e dos aquíferos pode ser alterado quando se faz uso desses recursos na lavra (desmonte hidráulico) e no beneficiamento, além de causar o rebaixamento do lençol freático. O rebaixamento de calha de rios com a lavra de seus leitos pode provocar a instabilidade de suas margens, causando a supressão das matas ciliares, além de possibilitar o descalçamento de pontes com eventuais rupturas. Com frequência, a mineração provoca a poluição do ar por particulados suspensos pela atividade de lavra, beneficiamento e transporte, ou por gases emitidos da queima de combustível. Outros impactos ao meio ambiente estão associados a ruídos, sobrepressão acústica e vibrações no solo associados à operação de equipamentos e explosões.

Todos os impactos anteriormente referidos podem ter efeitos danosos no 
equilíbrio dos ecossistemas, tais como a redução ou destruição de hábitat, afugentamento da fauna, morte de espécimes da fauna e da flora terrestres e aquáticas, incluindo eventuais espécies em extinção, interrupção de corredores de fluxos gênicos e de movimentação da biota, entre outros. Em relação ao meio antrópico, a mineração pode causar não apenas o desconforto ambiental, mas também impactos à saúde causados pela poluição sonora, do ar, da água e do solo. A desfiguração da paisagem é outro aspecto gerado pela mineração cujo impacto depende do volume de escavação e da visibilidade em razão de sua localização.

A foto abaixo ilustra a degradação ambiental gerada pela mineração na região de Guararema/SP.

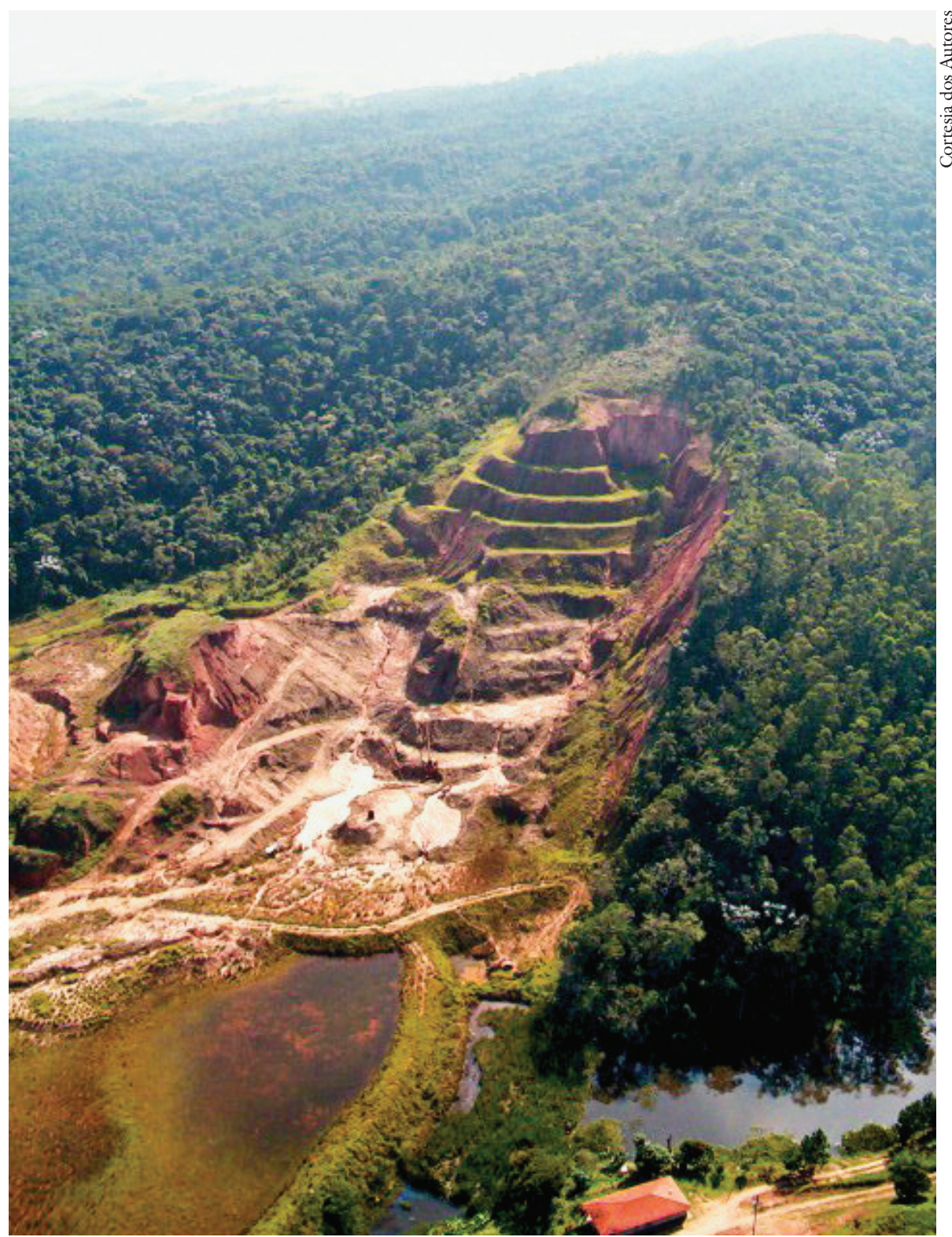

Degradação ambiental gerada pela mineração na região de Guararema(SP). 


\section{A mineração no Estado de São Paulo}

Apesar de as primeiras descobertas de recursos minerais brasileiros no final do século XVI terem ocorrido em território paulista, a economia paulista notabilizou-se inicialmente pela atividade agrícola, seguida do desenvolvimento industrial e da aceleração do crescimento urbano. Essas características, associadas às potencialidades dos terrenos geológicos, determinaram, definitivamente, o perfil atual da indústria mineral paulista, voltado notoriamente ao consumo interno para atender às indústrias dos setores cerâmico, siderúrgico, cimenteiro, vidreiro, entre outros, de insumos para agricultura e, de forma vigorosa, da construção civil.

Tabela 1 - Substâncias minerais produzidas no Estado de São Paulo - ano-base 2005

\begin{tabular}{|c|c|c|c|}
\hline Substância mineral & $\begin{array}{l}\text { Valor anual } \\
\text { R\$ x } 103\end{array}$ & $\%$ & $\begin{array}{c}\text { Quantidade } \\
\text { t x } 10^{3}\end{array}$ \\
\hline Areia & $846.293,0$ & 40,81 & $75.420,4$ \\
\hline Rocha britada & $548.317,4$ & 26,44 & $49.286,9$ \\
\hline Água mineral & $262.593,8$ & 12,66 & $2.108,0$ \\
\hline Calcário & $151.542,4$ & 7,31 & $9.755,4$ \\
\hline Areia industrial & $105.821,8$ & 5,10 & $3.604,3$ \\
\hline Fosfato & $71.252,8$ & 3,44 & 200,5 \\
\hline Caulim & $21.965,6$ & 1,06 & 139,4 \\
\hline Argilas comuns & $15.946,1$ & 0,77 & $4.661,5$ \\
\hline Filito & $12.251,3$ & 0,59 & 243,7 \\
\hline Feldspato & $6.534,6$ & 0,32 & 33,6 \\
\hline Argilas plásticas & $6.506,7$ & 0,31 & 125,8 \\
\hline $\begin{array}{l}\text { Bentonita e argilas } \\
\text { descorantes }\end{array}$ & $6.394,7$ & 0,31 & 45,2 \\
\hline Dolomito & $5.900,0$ & 0,28 & 198,5 \\
\hline Rocha ornamental & $5.686,5$ & 0,27 & 269,1 \\
\hline Bauxita metalúrgica & $1.851,2$ & 0,09 & 131,8 \\
\hline Talco & $1.515,6$ & 0,07 & 56,3 \\
\hline Quartzito industrial & 834,4 & 0,04 & 21,9 \\
\hline Argilas refratárias & 761,6 & 0,04 & 65,5 \\
\hline Bauxita refratária & 574,3 & 0,03 & 18,8 \\
\hline Ferro & 572,9 & 0,03 & 74,7 \\
\hline Turfa & 527,4 & 0,03 & 9,4 \\
\hline Cobre & 14,5 & 0,01 & 0,183 \\
\hline Manganês & 11,6 & - & 0,118 \\
\hline Calcita & 4,7 & - & 0,686 \\
\hline Total & $2.073 .807,4$ & 100,00 & $146.472,7$ \\
\hline
\end{tabular}

Fonte: Cabral Junior et al. (2008). 
A grande maioria dos municípios de São Paulo conta com alguma produção mineral, legalizada ou não, e as características geológicas do território paulista, associadas às demandas decorrentes do crescimento urbano e industrial, têm propiciado a nucleação da atividade de mineração em zonas específicas, promovendo a formação de polos produtores regionais com o adensamento de áreas impactadas pela extração mineral, tais como a Região Metropolitana de São Paulo (RMSP), o cinturão Sorocaba-Itu-Campinas, o Vale do Paraíba, o Vale do Ribeira e municípios adjacentes de Itapeva, Apiaí e Capão Bonito.

De acordo com Cabral Junior et al. (2008), em determinadas regiões as aglomerações de empresas de mineração chegam a constituir arranjos produtivos locais de base mineral, tais como as inúmeras aglomerações minerocerâmicas que integram a produção de argilas e a fabricação de produtos de cerâmica vermelha e revestimentos. Um desses aglomerados acompanha a Depressão Periférica Paulista, constituindo uma faixa contínua que se estende da região de Itapeva até São João da Boa Vista. Outra aglomeração se situa no oeste paulista, associada às faixas lindeiras dos rios Paraná, Tietê e Paranapanema.

Com raras exceções, a indústria mineral paulista apresenta deficiências tecnológicas, especialmente quando se trata da pequena empresa que corresponde à grande maioria do setor produtivo no Estado. Grande parte das minerações ressente-se de investimentos na pesquisa geológica das jazidas e na caracterização tecnológica dos minérios, no planejamento das operações de lavra, beneficiamento e recuperação ambiental, entre outros fatores.

A falta de ações de planejamento por parte dos poderes públicos e a carências aqui referidas têm gerado conflitos da atividade com outras formas de uso do solo, em muitos casos com desconforto e riscos às comunidades circunvizinhas. Além disso, a falta de controle e a não recuperação ambiental satisfatória das áreas mineradas têm causado uma série de outros impactos indesejáveis ao meio ambiente.

Como agravante dessa situação, a ilegalidade no setor ainda é significativa. Segundo a declaração do chefe do $2^{\circ}$ Distrito São Paulo do Departamento Nacional de Produção Mineral, Enzo Luís Nico Júnior, na edição de 12.7.2005 do jornal Folba de S.Paulo, existiam na ocasião cerca de 2.500 lavras autorizadas no Estado de São Paulo e havia indicação da existência de cerca de três mil mineradoras clandestinas.

\section{Prevenção e mitigação dos impactos}

Como instrumento previsto na Política Nacional de Meio Ambiente, a prevenção e a mitigação dos impactos da mineração sobre o meio ambiente no Estado de São Paulo vêm se fazendo por meio do licenciamento ambiental, com base no planejamento do empreendimento consubstanciado nos documentos denominados Relatório de Controle Ambiental (RCA), Plano de Controle Ambiental (PCA), Relatório Ambiental Preliminar (RAP), Estudo de Impacto Ambiental (EIA) e Relatório de Impacto Ambiental (Rima), a serem apresentados conforme 
os critérios estabelecidos na Resolução n.51, de 12 de dezembro de 2006, da Secretaria do Meio Ambiente.

A exigência de RAP ou EIA/Rima aplica-se aos empreendimentos novos sempre que o órgão ambiental considerar que haverá impacto ambiental significativo ou quando a área de extração for superior a 20 ha ou o volume total de material a ser extraído, incluindo minério e estéril, ultrapassar $5.000 .000 \mathrm{~m}^{3}$. Também haverá essa exigência quando for prevista supressão de vegetação nativa acima de 5 ha, houver intervenção em nascentes ou cursos d'água inseridos em mananciais de abastecimento público, a área estiver inserida em Zona de Amortecimento de Unidades de Conservação de Proteção Integral, nos termos da Lei Federal n.9.985/00 ou e se houver extração de rochas carbonáticas em regiões com evidências de fenômenos cársticos.

Para as minerações existentes na data da publicação do Regulamento da Lei n.997/76, a Resolução SMA n.51/06 prevê a obrigação de o empreendedor solicitar a Licença de Operação, apresentando um Plano de Recuperação de Área Degradada (Prad). Já nos casos de empreendimentos desativados, que não foram objeto de licenciamento ambiental, o responsável foi compelido a apresentar o projeto de revegetação para aprovação do DEPRN (atual Cetesb) e providenciar a recuperação da área degradada.

Outro instrumento da Política Nacional de Meio Ambiente empregado pelo Estado de São Paulo refere-se ao "Programa de Recursos Minerais e Meio Ambiente" que vem sendo desenvolvido pelo Instituto Geológico (IG), vinculado à Secretaria do Meio Ambiente, visando à definição de zoneamentos ambientais minerários e elaboração de planos diretores regionais de mineração.

O primeiro trabalho concluído pelo IG em 1997 foi direcionado ao Vale do Paraíba com o "Projeto Paraíba do Sul - Potencialidade de Areia", entre Jacareí e Roseira. O objetivo do projeto foi subsidiar o estabelecimento de normas técnicas e procedimentos de licenciamento ambiental e o zoneamento ambiental da mineração de areia, por meio da definição de áreas próprias para exploração mineral. Nesse estudo, foi realizada uma síntese dos trabalhos anteriores relativos à exploração mineral e ao planejamento integrado em razão do desenvolvimento econômico e ambiental da região, complementado com uma coletânea das legislações municipais relativas à atividade de exploração dos recursos minerais e de uso do solo. A definição e a delimitação da zona de potencial de areia basearam-se no estabelecimento dos limites das construções eminentemente arenosas ou do cinturão meândrico, pertencentes ao Sistema Fluvial Meandrante Holocênico do Rio Paraíba do Sul.

Com base nesse estudo do IG, a Secretaria do Meio Ambiente estabeleceu o zoneamento ambiental para mineração de areia na várzea do Rio Paraíba do Sul, no subtrecho inserido nos municípios de Jacareí, São José dos Campos, Caçapava, Taubaté, Tremembé e Pindamonhangaba, conforme disposto na Resolução SMA n.28/99. Nesse subtrecho, os novos empreendimentos foram dispensados 
de EIA/Rima para seu licenciamento, de acordo com a Resolução SMA n.03/99, podendo-se extrair areia dentro dos limites da zona de mineração, respeitando-se as zonas de proteção, que visam resguardar o ecossistema formado pelo Rio Paraíba do Sul, a vegetação remanescente preservada e, especialmente, as associadas aos meandros abandonados, assim como as zonas de conservação da várzea, que visam proteger e conservar a planície aluvionar, dessa forma garantindo a permeabilidade dos solos e a não contaminação das águas, mediante usos compatíveis com sua função ecológica. A zona de recuperação aplica-se aos empreendimentos em atividade ou exauridas, compreendendo as áreas definidas como prioritárias à recuperação ambiental, objetivando compatibilizá-las com os usos urbano, agropecuário ou de preservação, segundo sua localização específica.

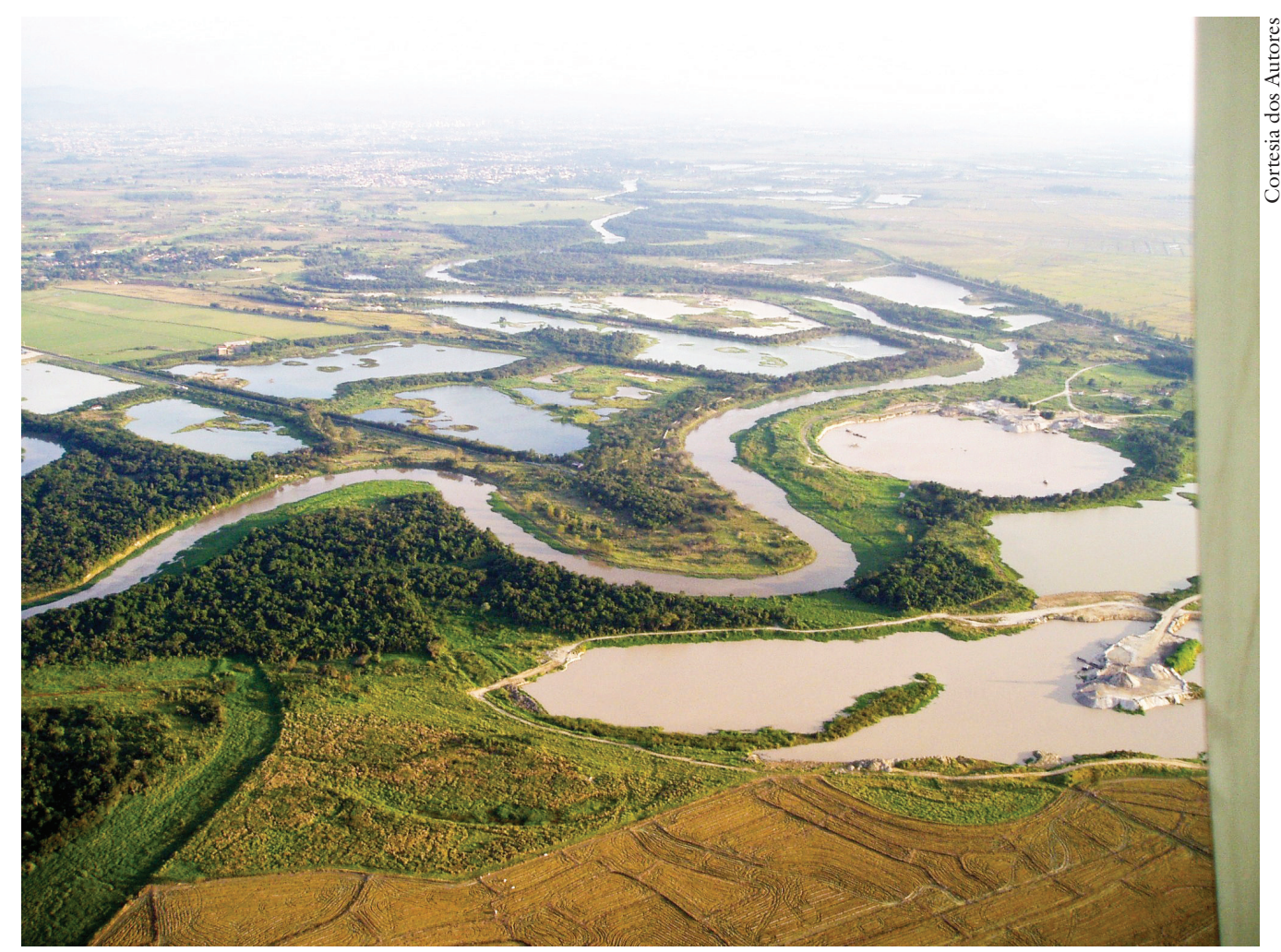

Mineração de areia na várzea do Rio Paraíba do Sul (SP).

De acordo com Reis et al. (2006), em trabalho elaborado com o propósito de investigar as consequências da extração de areia em larga escala no balanço hídrico climatológico do Vale do Paraíba, no trecho paulista a área de lagos artificiais originados pela extração de areia evoluiu de 591,4 ha em 1993 para 1.726,5 ha em 2003. Neste ano, registrou-se uma perda de água para a atmosfera pela evaporação das cavas de $19.157 .022 \mathrm{~m}^{3} /$ ano, que seria suficiente para abastecer uma cidade com 326.318 habitantes. Outro aspecto observado por Reis (2009) refere-se à constatação do avanço da lavra para além dos limites da zona de mineração no município de Tremembé. 
Em trabalho de avaliação da recuperação ambiental da mineração de areia na várzea do Paraíba do Sul, no trecho entre Jacareí e Pindamonhangaba, a Secretaria do Meio Ambiente concluiu que a recuperação vegetal foi qualificada como ruim ou regular na maioria dos empreendimentos (São Paulo, 2008). As questões relacionadas à qualidade das águas e dos sedimentos das cavas, os processos de eutrofização e as possibilidades de usos futuros não foram avaliados.

Segundo a Resolução SMA n.42/96, que disciplina o licenciamento ambiental dos empreendimentos minerários de extração de areia na Bacia Hidrográfica do Rio Paraíba do Sul, as medidas de recuperação da área degradada se atêm à estabilização do meio físico e à revegetação das margens das cavas, e as áreas não consideradas pela legislação vigente como de preservação permanente, dependendo da intenção de usos futuros do solo, poderão ser utilizados para plantio homogêneo de espécies exóticas e nativas, ou outras alternativas, mediante aprovação do projeto pela SMA, desde que cumpram a função de proteção do solo e dos recursos hídricos.

$\mathrm{Na}$ avaliação da recuperação de áreas degradas por mineração na Região Metropolitana de São Paulo, Bitar et al. (2000) concluíram que há uma evidente dissociação entre as medidas praticadas e aquelas preconizadas nos planos de recuperação elaborados pelas empresas de mineração. A maior parte dos trabalhos de recuperação de áreas degradadas praticados em minas ativas na RMSP tinha caráter incipiente, baseando-se especialmente na execução de medidas restritas de revegetação, visando, em especial, atenuar o impacto visual gerado. As minas desativadas favoreceram a ocupação desordenada, e cavas remanescentes, total ou parcialmente inundadas, encontravam-se permanentemente sujeitas à deposição desordenada de resíduos, que podem gerar a contaminação do solo e das águas superficiais ou subterrâneas e colocar em risco a saúde da população do entorno.

Outros passivos ambientais associados à poluição do solo e das águas superficiais ou subterrâneas por substâncias perigosas à saúde humana foram estudados por Bernardino et al. (2004), que constataram que, embora as atividades de mineração e metalurgia tenham cessado em 1996, as populações do Alto Vale do Ribeira ainda convivem com várias fontes de contaminação ambiental, em especial de chumbo e arsênio, tipicamente originadas da atividade de extração, beneficiamento e refino mineral. As emissões de metais para atmosfera e subsequente deposição dos particulados foram responsáveis pela contaminação dos solos em áreas habitadas por essas populações. Processos de lixiviação levaram também esses contaminantes aos sedimentos dos rios da região, que chegaram ao estuário do Rio Ribeira de Iguape.

\section{Perspectivas}

Se considerarmos o histórico da mineração no Estado de São Paulo e as ações do poder público no sentido de estancar e reverter o quadro de degradação gerado por essa atividade, não se vislumbra, em curto prazo, o desenvolvimento 
dessa atividade de forma a assegurar o suprimento futuro de matérias-primas minerais e garantir a qualidade das condições ambientais.

Em que pese a contribuição representada por forças de mercado e algumas iniciativas voluntárias das empresas, foram as demandas impostas pela legislação aquelas que realmente fizeram avançar a gestão ambiental (Centro de Tecnologia Mineral, 2007). Mesmo assim, há um grande caminho a percorrer que passa necessariamente pela promoção de ações e projetos setoriais dirigidos ao planejamento, ordenamento e aprimoramento tecnológico da atividade de mineração no Estado, além do aprimoramento dos instrumentos de licenciamento e fiscalização.

Com elevada frequência, a mineração vem sendo desenvolvida em locais sensíveis ambientalmente e importantes para a preservação da biodiversidade, dos recursos hídricos, da paisagem ou de demais recursos naturais, que mostram equívocos técnicos de se considerar previamente essa atividade como sendo de baixo impacto ambiental. Cabe ressaltar que, em caso de exploração mineral em área de preservação permanente, o enquadramento como atividade de baixo impacto ambiental está fora de cogitação.

A extração de areia em leito de rio, de areia e de argila em áreas de várzea ou nas margens de cursos d'água ou lagos, de rochas variadas usadas na construção civil em topos de morro ou encostas íngremes atingindo nascentes, cursos d'água e a vegetação nativa são comuns no Estado de São Paulo, e a grande maioria dos empreendimentos obteve licença de funcionamento sem ter apresentado o EIA/ Rima. A extração de areia por meio de jateamento de água no solo (desmonte hidráulico) também é comum, e, da mesma forma, a maior parte dos empreendimentos não tem EIA/Rima.

Os Planos de Recuperação de Áreas Degradadas (Prad), apesar de exigidos desde 1989, são relativamente recentes nos empreendimentos e há uma evidente dissociação entre as medidas praticadas e aquelas preconizadas nesses planos. A maior parte dos trabalhos de recuperação de áreas degradadas pela mineração que se tem registrado no Estado de São Paulo tem caráter incipiente e se baseia especialmente na execução de medidas restritas de revegetação, visando atenuar o impacto visual gerado.

O planejamento da lavra e o emprego de equipamentos podem reduzir os impactos durante a operação da atividade, porém não possibilitam a recuperação das condições originais da área, restringindo o uso futuro da área e alterando suas funções ambientais primitivas. Esses fatos se devem especialmente ao déficit de volume de materiais não comercializados ou rejeitos que podem ser empregados para preencher as cavas resultantes das escavações e recompor a topografia do terreno.

A maioria das cavas de mineração abertas em várzeas para extração de areia ou argila resulta em lagoas que, apesar de destinadas ao uso de piscicultura ou pesque-pague na maioria dos planos de recuperação, acabam com frequência abandonadas e em processo de eutrofização. Geralmente, essas situações se repe- 
tem ao longo da mesma várzea, criando um adensamento de lagoas e alterando significativamente o ambiente original em razão dos impactos cumulativos.

Já a extração de areia em calha de rio tem causado o rebaixamento de seu leito e desequilíbrio do meio, provocando o solapamento e a erosão das margens. As intervenções necessárias para promover artificialmente a contenção desses processos são impactantes e onerosas de tal forma que, em geral, essas áreas ficam abandonadas à mercê de sucessões naturais até que estabeleça um novo equilíbrio.

Grandes cavas de pedreiras ou de extração de areia por desmonte hidráulico, próximas a centros urbanos, têm sido reaterradas com resíduos inertes provenientes de entulho da construção civil, cuja adequação tem sido contestada em razão da total falta de controle da qualidade desses resíduos, que podem conter substâncias não inertes e, eventualmente, perigosas, que podem poluir as águas superficiais ou subterrâneas e colocar em risco a saúde humana.

Em muitas situações, as frentes de escavação para a extração de minério avançam demasiadamente, dando origem às cavas limitadas por taludes íngremes e elevados, cujo abatimento da inclinação se torna problemático ou inviável, uma vez que essa medida implica escavação adicional vultosa, ampliando a área degradada e, eventualmente, atingindo áreas florestadas ou terrenos além do limite permitido para a lavra.

Tais situações podem ter origem na deficiência do plano de recuperação ou de fiscalização sistemática para a verificação do cumprimento dos cronogramas estabelecidos nos projetos. A postergação de implementação de medidas de recuperação para a fase final de lavra, próxima à sua exaustão, implica aumento significativo de custos justamente numa fase de redução de receita, estimulando o abandono ou o cumprimento parcial das obrigações.

Como comentado anteriormente, as características geológicas do território paulista associadas às demandas decorrentes do crescimento urbano e industrial têm propiciado a nucleação da atividade de mineração em zonas específicas, promovendo a formação de polos produtores regionais com o adensamento de áreas impactadas pela extração mineral. Na tentativa de dar conta dessa questão, o Instituto Geológico vem desenvolvendo o "Programa de Recursos Minerais e Meio Ambiente" visando à definição de zoneamentos ambientais minerários e elaboração de planos diretores regionais de mineração e compatibilizar essa atividade com o desenvolvimento sustentável.

Os exemplos de zoneamentos aprovados pela Secretária do Meio Ambiente, como aquele da Bacia do Rio Pará́ba do Sul, onde o licenciamento de novos empreendimentos é dispensado de EIA/Rima, com base na Resolução SMA n.03/99, têm, porém, gerado apreensão quanto aos efeitos sobre o meio ambiente do adensamento de cavas de mineração ao longo da várzea desse curso d'água, que ainda não foram devidamente avaliados.

Da forma como os trabalhos foram desenvolvidos, verifica-se que os problemas relacionados à extração de areia no Vale do Paraíba do Sul estão relacionados 
à ausência de estudos efetivos sobre as características dos ecossistemas (composição, estrutura, dinâmica), seus aspectos funcionais e fragilidades, que pudessem fundamentar realmente uma avaliação procedente das consequências da atividade minerária sobre os ambientes atingidos.

Diante desse contexto, o zoneamento ambiental para mineração de areia da Bacia do Rio Paraíba do Sul não pode ser equiparado ao EIA/Rima, tendo em vista a abrangência e o detalhamento dos estudos e levantamentos realizados, que, como já citado, não diagnosticou adequadamente os ecossistemas, não avaliou o passivo ambiental e os impactos no meio ambiente dos empreendimentos atuais e futuros.

Pelas razões citadas, pode-se concluir que o licenciamento da atividade de mineração, da forma como vem sendo conduzido no Estado de São Paulo, não está atingindo satisfatoriamente os objetivos da Política Nacional do Meio Ambiente. Da mesma forma, a ordem imposta pela Constituição Federal de que aquele que explorar recursos minerais fica obrigado a recuperar o meio ambiente degradado, de acordo com solução técnica exigida pelo órgão público competente, não vem sendo atendida a contento.

\section{Referências}

BERNARDINO, F. R. et al. Exposição humana à contaminação por chumbo e arsênio no Vale do Ribeira. In: ENCONTRO DA ANPPAS, 2, maio 2004, Campinas.

BITAR, O. Y. Avaliação da recuperação de áreas degradadas por mineração na Região Metropolitana de São Paulo. São Paulo, 1997. 185p. Tese (Doutorado) - Escola Politécnica, Universidade de São Paulo.

BITAR, O. Y. et al. Geotecnologia: tendências e desafios. São Paulo em Perspectiva, v.14, n.3, p.78-90, 2000.

CABRAL JUNIOR, M. Caracterização dos arranjos produtivos (APLs) de base mineral no Estado de São Paulo: subsídios à mineração paulista. Campinas, 2008. 283p. Tese (Doutorado em Geociências) - Instituto de Geociências, Universidade Estadual de Campinas.

CABRAL JUNIOR, M. et al. A mineração no Estado de São Paulo: situação atual, perspectivas e desafios para o aproveitamento dos recursos minerais. Geociências, v.27, n.2, p.171-92, 2008.

CENTRO DE TECNOLOGIA MINERAL. Tendências Tecnológicas Brasil 2015: Geociências e Tecnologia Mineral. Ed. Francisco R. C. Fernandes, Adão B. da Luz, Gerson M. M. Matos, Zuleica Carmen Castilhos. Rio de Janeiro: Cetem/MCT, 2007. 380p. il.

DEPARTAMENTO NACIONAL DA PRODUÇÃO MINERAL - DNPM. Anuário Mineral Brasileiro 2006. Brasília: Departamento Nacional da Produção Mineral, 2006, Disponível em: <http://www.dnpm.bov.br>. Acesso em: 7 fev. 2010.

FOLHA DE S.PAULO. Ilegais faturam US\$ 9 bi ao ano. 12 jul. 2005 
INSTITUTO DE PESQUISA TECNOLÓGICAS DO ESTADO DE SÃO PAULO (IPT). Mineração \& município: bases para planejamento e gestão de recursos minerais. Coord. Luiz Carlos Tanno, Ayrton Sintoni. São Paulo: Instituto de Pesquisas Tecnológicas, 2003.

INSTITUTO GEOLÓGICO (IG). Projeto Paraíba do Sul: potencialidade de areia. Disponível em: <http://www.igeologico.sp.gov.br>. Acesso em: 7 fev. 2010.

REIS, B. J. Revisão do zoneamento ambiental minerário do município de Tremembé - SP com a utilização de imagem de alta resolução espacial. In: SEMINÁRIO DE RECURSOS HÍDRICOS DA BACIA HIDROGRÁFICA DO PARAÍBA DO SUL: RECUPERAÇÃO DE ÁREAS DEGRADADAS, SERVIÇOS AMBIENTAIS E SUSTENTABILIDADE, 2, 2009, Taubaté, Brasil, Anais... São Paulo: IPABHi, 9-11 dez. 2009. p.273-8.

REIS, B. J. et al. Desenvolvimento de um banco de dados georreferenciados para avaliação de atividades minerarias na planície aluvial do rio Paraíba do Sul. Revista Biociências, Taubaté, v.12, n.12, p.34-42, jan./jun. 2006.

SÃO PAULO (Estado). Secretaria de Meio Ambiente. Avaliação da recuperação ambiental da mineração de areia para aperfeiçoar os instrumentos de gestão: várzea do Paraíba do Sul - trecho Jacareí Pindamonhangaba. Secretaria de Estado do Meio Ambiente. Coordenadoria de Planejamento Ambiental; coordenação Lina Maria Aché, Sônia Aparecida Abissi Nogueira e Neide Araújo; equipe técnica executora Antônio José Dias et al. São Paulo: SMA, 2008.

RESUMO - De modo geral, a mineração causa impacto significativo ao meio ambiente, pois quase sempre o desenvolvimento dessa atividade implica supressão de vegetação, exposição do solo aos processos erosivos com alterações na quantidade e qualidade dos recursos hídricos superficiais e subterrâneos, além de causar poluição do ar, entre outros aspectos negativos. A prevenção e a mitigação desses impactos no Estado de São Paulo se fazem por meio do licenciamento ambiental. Outra forma de gestão ambiental do Estado refere-se aos programas que visam à definição de zoneamentos ambientais minerários e elaboração de planos diretores regionais de mineração. Há, porém, evidente dissociação entre as ações praticadas e aquelas preconizadas nos projetos, restringindo a recuperação da área degradada a medidas que apenas atenuam o impacto visual. Este artigo apresenta considerações sobre o tema e o desafio de o setor se adequar à Constituição Federal e à Política Nacional de Meio Ambiente.

PALAVRAS-CHAVE: Mineração, Impacto ambiental, Gestão, Recuperação de área degradada.

ABSTRACT - Generally, mining causes significant impact over the environment, since this activity often involves suppression of vegetation, soil exposure and erosion resulting in important changes in the quantity and quality of surface and ground-waters and in air pollution, among other negative effects. The prevention and mitigation of these impacts in the State of Sao Paulo are made through the environmental licensing. Another way of environmental management includes programs like mining and environmental zoning and regional mining director plans. But there is clear dissociation between the actions effectively taken and those recommended in the projects, limiting the recovery 
of degraded areas to measures that only attenuate the visual impact. This paper presents considerations on the subject and challenges of the industry to adapt to the Federal Constitution and the National Policy on Environment.

KEYWORDS: Mining, Environmental impact, Management, Rehabilitation of degraded areas.

Andréa Mechi é geóloga pela Universidade Estadual Paulista (Unesp), especialista em Engenharia Ambiental pela Universidade Federal do Rio de Janeiro (UFRJ) e mestre em Gestão Ambiental pela Universidade Estadual de Campinas (Unicamp). Trabalha desde 1998 como assistente técnico do Ministério Público do Estado de São Paulo. @ - andreamechi@hotmail.com

Djalma Luiz Sanches é geólogo pela Universidade de São Paulo (USP) e especialista em Gestão Ambiental pela Universidade Estadual de Campinas (Unicamp). Trabalha desde 1998 como assistente técnico do Ministério Público do Estado de São Paulo. @ - djalmasanches@hotmail.com

Recebido em 24.2.2010 e aceito em 4.3.2010. 